\title{
PESQUISA QUANTITATIVA E QUALITATIVA EM SOCIOLINGUÍSTICA: DADAÍSMO METODOLÓGICO?
}

Caroline Rodrigues Cardoso

\section{RESUMO}

A confluência entre pesquisas quantitativas e qualitativas na Sociolinguística é um dadaísmo metodológico? O cerne da discussão aqui não é a epistemologia, pois parto do pressuposto de que a Sociolinguística estuda a língua atrelada ao social. Busco demonstrar que o enfoque metodológico depende da pergunta de pesquisa, ou seja, do tema a respeito do qual se desenvolve uma tese.

PALAVRAS-CHAVE: Sociolinguística; metodologia; pesquisa quali-quanti.

Podemos dizer que o fato de existirem muitas formas de ver a realidade não implica necessariamente que existam muitas "verdades" alternativas.

(BORGES NETO, 2004a) ${ }^{1}$

$s$ reflexóes aqui apresentadas ganharam força no segundo semestre de 2008, quando cursei a disciplina Metodologia: análise de discurso e pesquisa etnográfica, ministrada pela Profa. Dra. Cibele Brandão, no Programa de Pós-graduação em Linguística do Departamento de Linguística, Línguas Clássicas e Português da Universidade de Brasília (PPGL/LIP/UnB). Procuro pensar em uma possível confluência entre metodologia quantitativa e

1 BORGES NETO, José. Ensaios de filosofia da linguistica. São Paulo: Parábola, 2004a. 
qualitativa na pesquisa sociolinguística - isso seria um dadaísmo ${ }^{2}$ metodológico? Borges Neto $(2004 \mathrm{a})^{3}$ fala em dadaísmo epistemológico remetendo a Feyerabend (1975), porque objetiva discutir de que trata a Linguística. Aqui, o cerne da questão não é a epistemologia, porque já se parte do pressuposto de que a Sociolinguística é a ciência que estuda a língua atrelada ao social. Sabe-se que o próprio surgimento desse ramo dentro da Linguística subjaz a olhares diferenciados sobre o objeto de estudo e, consequentemente, implica métodos e/ou técnicas também diferenciados. Assim, entende-se que "se os pontos de partida são diversos, os resultados serão igualmente diversos" (DEMO, 1987, p.15) ${ }^{4}$.

Metodologia tem sido considerada um conjunto de métodos e técnicas utilizados para construção do conhecimento por meio de pesquisa (SILVA \& SILVEIRA, 2007) ${ }^{5}$, ou seja, é uma preocupação instrumental (DEMO, 1987) ${ }^{6}$. Alguns (socio)linguistas defendem que metodologias quali e quanti são excludentes. Outros, que tudo depende do tópico a ser investigado. Entendo que um enfoque metodológico $x$ e/ou $y$ depende da pergunta de pesquisa, ou seja, do tema a respeito do qual se desenvolve uma tese. A pergunta levará ao uso de métodos e/ou técnicas abarcadas pela visão epistemológica do pesquisador (JOHNSTONE, 20007 MASON, 2002 ${ }^{8}$ ). Assim, "é importante percebermos que a ideia que fazemos da realidade de certa maneira precede a ideia de como tratá-la” (DEMO, 1987, p. 19) ${ }^{9}$.

2 O Dadaísmo foi um movimento de vanguarda caracterizado pela oposição a qualquer tipo de equilíbrio, pela combinação de pessimismo irônico e ingenuidade radical, pelo ceticismo absoluto e improvisação. Enfatizou o ilógico e o absurdo. Entretanto, apesar da aparente falta de sentido, o movimento protestava contra a loucura da guerra. Assim, sua principal estratégia era mesmo denunciar e escandalizar. Disponível em: <http://pt.wikipedia.org.> . Acesso em: 28 jun. 2009.

3 BORGES NETO, José. Ensaios de filosofia da linguística. São Paulo: Parábola, $2004 a$.

4 DEMO, Pedro. Introdução à metodologia da ciência. São Paulo: Atlas, 1987.

5 SILVA, José Maria da; SILVEIRA, Emerson Sena da. Apresentação de trabalhos acadêmicos: normas e técnicas. Petrópolis, RJ: Vozes, 2007.

6 DEMO, Pedro. Introdução à metodologia da ciência. São Paulo: Atlas, 1987.

7 JONHSTONE, Barbara. "Thinking about methodology". In: Qualitative methods in Sociolinguistics. New York: Oxford University Press, 2000. p. 20-38.

8 MASON, Jennifer. "Designing qualitative research". In: Qualitative researching. London: Sage, 2002. p. 24-47.

9 DEMO, Pedro. Introdução à metodologia da ciência. Sáo Paulo: Atlas, 1987. 
Um pesquisador maduro deve ter consciência dos seus objetivos, das suas hipóteses, do caminho a ser percorrido, com potencialidades e possíveis limitações. A mudança de caminho, se necessária for, nem sempre implica mudança de objetivos, mas a mudança de objetivos implica mudança de caminhos.

Segundo Demo (1987), a ciência é intrinsecamente a atitude questionadora frente à realidade, e a metodologia seria a forma de captar respostas. Portanto, "não há amadurecimento científico sem amadurecimento metodológico” (DEMO, 1987, p. 25) ${ }^{10}$. Uma possível inquietação acadêmica leva esse pesquisador mais maduro a experimentaçóes 'dadaístas', entendidas como agitação, insatisfação, rompimento de um status quo, abertura ao novo.

Estudos epistemológicos têm demonstrado que, durante muito tempo, vigorou, no mundo acadêmico, o paradigma cartesiano, responsável pelo desenvolvimento de doutrinas e pressupostos materialistas, fundamentado em um pensamento filosófico positivista, que parte do princípio da neutralidade e da objetividade de leis e fenômenos mensurados matematicamente.

Descartes (1596-1650) propunha um fazer científico essencialmente prático e não especulativo a partir de um bom método, universal e inspirado no rigor matemático e racionalista. $\mathrm{O}$ método seria um instrumento que, bem manejado, levaria o homem à verdade. Esse método consistia em aceitar apenas o que é objetivo e irrefutável e, consequentemente, eliminar todo o conhecimento subjetivo ou sujeito a controvérsias. Essa postura cartesiana objetivava abranger, numa perspectiva de conjunto unitário e claro, todos os problemas sujeitos à investigação científica.

Quanto ao Positivismo (Augusto Comte, 1798-1857), este se ocupa daquilo que é verificável empiricamente, e isso significa aquilo que é medido matematicamente. Seu sentido está no próprio nome - positivo -, cujo significado é real em oposição a ideal, objetivo em oposição a subjetivo, relativo em oposição a absoluto, preciso em oposição a impreciso. Desse ponto de vista, no campo de estudos da linguagem, uma sentença só é verdadeira se for empiricamente verificada, ou seja, se está correlacionada com os fatos da realidade. Por exemplo, considerando a contextualização do início deste texto, a sentença (1) "Caroline Cardoso é aluna de pós-graduação da UnB” é verdadeira, já que é empiricamente verificável, mas a sentença (2) "Cibele Brandão é aluna

${ }_{10}$ DEMO, Pedro. Introdução à metodologia da ciência. São Paulo: Atlas, 1987. 
de pós-graduação da UnB” não é verdadeira por não ser verificável no mundo real. Assim sendo, a análise do significado pressupóe uma condição objetiva e uma verificação possível no mundo real.

De outro ponto de vista, a sentença (2) poderia ser verdadeira, dependendo do contexto. Também poderia se considerar que a professora Cibele algum dia foi aluna da pós-graduação na UnB e alguém não sabe que ela já defendeu tese. Então, essa sentença poderia certamente ser produzida como verdadeira, pois Cibele um dia foi aluna da pós-graduação da UnB (BORGES NETO, 2004a ${ }^{11}, 2004 \mathrm{~b}^{12}$; DENZIN \& LINCOLN, 2006 ${ }^{13}$; SCHWANDT, 2006 ${ }^{14}$; SOUZA, 2007 ${ }^{15}$ ).

No paradigma positivista, dominante na ciência por muito tempo, pesquisar significa centralizar-se num programa de investigação científica baseado em um conjunto de proposiçóes/hipóteses testáveis, seguindo uma metodologia específica e métodos estatísticos que possam validar numericamente as hipóteses (BORGES NETO, 2004a ${ }^{16}, 2004 b^{17}$; SILVA \& SILVEIRA, $2007^{18}$; SOUZA, $2007^{19}$ ).

No segundo quarto do século XX, tem início uma crise interior da ciência mecanicista, racionalista e ideal. Outra postura passou a ocupar destaque no campo científico a partir de transformaçóes como a passagem da física clássica

11 BORGES NETO, José. Ensaios de filosofia da linguística. São Paulo: Parábola, 2004a.

12 BORGES NETO, José. "O empreendimento gerativo". In: MUSSALIM, Fernanda; BENTES, Anna Christina. Introdução à linguistica: fundamentos epistemológicos. São Paulo: Cortez, 2004b. p. 93-129.

13 DENZIN, Norman K.; LINCOLN, Yvonna S. "A disciplina e a prática da pesquisa qualitativa”. In: O planejamento da pesquisa qualitativa: teorias e abordagens. Porto Alegre: Artmed, 2006. p. 15-39.

14 SCHWANDT, Thomas A. "Interpretativismo, hermenêutica e construcionismo social”. In: DENZIN, Norman K.; LINCOLN, Yvonna S. O planejamento da pesquisa qualitativa: teorias e abordagens. Porto Alegre: Artmed, 2006. p. 193-217.

15 SOUZA, Denizard de. Ensaios de espiritualidade e cultura contemporânea. Brasília: LGE, 2007.

16 BORGES NETO, José. Ensaios de filosofia da linguística. São Paulo: Parábola, 2004a.

17 BORGES NETO, José. “O empreendimento gerativo”. In: MUSSALIM, Fernanda; BENTES, Anna Christina. Introdução à linguística: fundamentos epistemológicos. São Paulo: Cortez, 2004b. p. 93-129.

18 SILVA, José Maria da; SILVEIRA, Emerson Sena da. Apresentação de trabalhos acadêmicos: normas e técnicas. Petrópolis, RJ: Vozes, 2007.

19 SOUZA, Denizard de. Ensaios de espiritualidade e cultura contemporânea. Brasília: LGE, 2007. 
newtoniana para a física quântica, da biologia organicista para a biologia molecular, da fragmentação do saber para a interdisciplinaridade, da cerebrologia para a não localidade quântica da mente, da tecnologia analógica para a digital.

A postura cartesiana dá lugar a outras interpretaçóes do mundo natural no âmbito das próprias ciências positivas. Daí uma revisão crítica da ciência por parte dos cientistas, dividida em duas fases principais: uma de crítica à ciência e ao positivismo; outra de reconstrução filosófica em relação com exigências mais ou menos metafísicas ou espiritualistas (GILL, 2002 ${ }^{20}$; DENZIN \& LINCOLN, 2006²1; SCHWANDT, 2006 22; SOUZA, 200723).

Então, as ciências tidas como factuais culturais, como a Psicologia Social, a Sociologia, a Economia, a História e as ciências humanas de modo geral, passam por um período de reflexão e reformulação de metodologias e práticas de pesquisa, combinando uma tradição de conhecimento fragmentado e analítico com uma nova realidade humana e social. Essa reformulaçáo pretende na contemporaneidade um fazer científico holístico, interpretativo, sistêmico, subjetivo e, ao mesmo tempo, orientado para uma racionalidade complexa e integrativa.

Como enfatiza Levy (1999) ${ }^{24}$, tende-se a uma suplantação "dos antigos critérios de objetividade e universalidade abstrata" para tratar do holismo e da complexidade do pensamento (MORIN, 2006) ${ }^{25}$. Assim, podemos considerar que há pelo menos duas posturas científicas vigorando no meio acadêmico atualmente: uma com foco na especialidade, na descontextualizaçâo e nas generalizaçóes; outra em busca do holismo, de uma visão do todo, do conjunto, como bem enfatizam Levy (1999) ${ }^{26}$ e Bauman (2008) ${ }^{27}$.

20 GILL, Rosalind. "Análise de discurso”. In: BAUER, M. W.; GASKELL, G. (Orgs.). Pesquisa qualitativa com texto, imagem e som. Um manual prático. Petrópolis, RJ: Vozes, 2002.

21 DENZIN, Norman K.; LINCOLN, Yvonna S. "A disciplina e a prática da pesquisa qualitativa”. In:__. O planejamento da pesquisa qualitativa: teorias e abordagens. Porto Alegre: Artmed, 2006. p. 15-39.

22 SCHWANDT, Thomas A. "Interpretativismo, hermenêutica e construcionismo social". In: DENZIN, Norman K.; LINCOLN, Yvonna S. O planejamento da pesquisa qualitativa: teorias e abordagens. Porto Alegre: Artmed, 2006. p. 193-217.

23 SOUZA, Denizard de. Ensaios de espiritualidade e cultura contemporânea. Brasília: LGE, 2007.

24 LEVY, Pierre. Cibercultura. São Paulo: Ed. 34, 1999.

25 MORIN, Edgar. Introdução ao Pensamento Complexo. Porto Alegre: Sulina, 2006.

26 LEVY, Pierre. Cibercultura. São Paulo: Ed. 34, 1999.

27 BAUMAN, Zygmunt. A sociedade individualizada: vidas contadas e histórias vividas. Rio de Janeiro: Zahar, 2008. 
Deve-se ressaltar que essas posturas não são totalmente excludentes. Há cientistas que buscam equilibrar a visão objetivista com a subjetivista, obtendo resultados satisfatórios dentro daquilo que se propóem a fazer. Essa postura leva em consideração que realmente se pode lançar mão da subjetividade objetiva. Nas palavras de Schwandt (2006, p.197) ${ }^{28}$, “é possível compreender o significado subjetivo da ação (entender as crenças do ator, seus desejos, etc.), porém, de uma maneira objetiva”.

Há bastante perigo em ser subjetivo ou objetivo em demasia. $\mathrm{O}$ pesquisador precisa ter o cuidado de saber balancear sua postura metodológica ao investigar um assunto, pois "os números só adquirem significado quando colocados em contextos mais amplos, dentro de uma teoria, de conceitos; caso contrário são apenas números e podem servir a propósitos de manipulação" (SILVA \& SILVEIRA, 2007, p. 149) 29; e, também,

Para não interpretar equivocadamente o significado original, os intérpretes devem empregar algum tipo de método que lhes possibilite um afastamento de seus referenciais históricos. Quando corretamente empregado, o método é um meio que permite aos intérpretes alegar uma atitude puramente teórica de observador. (SCHWANDT, 2006, p. 197) ${ }^{30}$

A Linguística sofre dos mesmos problemas epistemológicos que as outras ciências tidas como sociais. Os cientistas dessa área, em geral, buscam uma bússola para estabelecer detalhadamente o caminho a percorrer numa investigação de cunho linguístico. E, em geral, têm a opção de homogeneizar o objeto de estudos e autonomizar a linguística ou a opção de heterogeneizar o objeto de estudos e interdisciplinarizar a linguística (BORGES NETO,

28 SCHWANDT, Thomas A. "Interpretativismo, hermenêutica e construcionismo social". In: DENZIN, Norman K.; LINCOLN, Yvonna S. O planejamento da pesquisa qualitativa: teorias e abordagens. Porto Alegre: Artmed, 2006. p. 193-217.

29 SILVA, José Maria da; SILVEIRA, Emerson Sena da. Apresentação de trabalhos acadêmicos: normas e técnicas. Petrópolis, RJ: Vozes, 2007.

30 SCHWANDT, Thomas A. "Interpretativismo, hermenêutica e construcionismo social”. In: DENZIN, Norman K.; LINCOLN, Yvonna S. O planejamento da pesquisa qualitativa: teorias e abordagens. Porto Alegre: Artmed, 2006. p. 193-217. 
2004a, p. 59) 31 . A história da aquisição do status de ciência, atribuído aos estudos linguísticos no início do século XX, coincidiu com a vigência do pensamento positivista lógico. Isso contribuiu para que Saussure e seus seguidores considerassem a língua de um ponto de vista estrutural, afirmando que "é o ponto de vista que cria o objeto" (SAUSSURE, 1993, p. 15) ) $^{32}$ e que

a Linguística tem relaçôes bastante estreitas com outras ciências, que tanto lhe tomam emprestados como lhe fornecem dados. [...] Por exemplo, a Linguística deve ser cuidadosamente distinguida da Etnografia e da Pré-História, onde a língua não intervém senão a título de documento [...]. (SAUSSURE, 1993, p. $13-14)^{33}$

Em geral, a pesquisa linguística tem se pautado no paradigma empirista por se utilizar basicamente de métodos experimentais para captação e análise de dados linguísticos sem levar em consideração algumas questôes importantes, como a inserção da língua num contexto humano e social com o fim básico de levar à comunicação ou, ainda mais partidariamente, à interação (inter+ação). Essa postura é baseada numa tradição saussuriana de análise estrutural, pautada em dicotomias, focada em fatores internos à própria língua e dimensionada na homogeneidade linguística.

Na década de 60, William Labov implementou um novo viés de estudos da língua, adicionando à visão essencialmente estruturalista o componente da heterogeneidade linguística. O que exatamente isso quis dizer? Que a língua passa a ser vista como um sistema heterogêneo, mutável, variável e dinâmico. E que estudar esse sistema significa considerar que fatores sociais podem afetar a estrutura linguística, além dos próprios fatores internos ao sistema.

Diferentemente do que afirma Pagotto $\left(2004\right.$, p. 49) ${ }^{34}$, o capítulo 8 do clássico livro de Labov $(2008)^{35}$ pode ajudar a entender que o fulcro de toda a discussão a respeito da superação de um paradigma saussuriano nos estudos

\footnotetext{
31 BORGES NETO, José. Ensaios de filosofia da linguística. São Paulo: Parábola, 2004a.

32 SAUSSURE, Ferdinand de. Curso de linguística geral. São Paulo: Cultrix, 1993.

33 SAUSSURE, Ferdinand de. Curso de linguística geral. São Paulo: Cultrix, 1993.

34 PAGOTTO, Emilio Gozze. Variação e (') identidade. Maceió: EDUFAL, 2004.

35 LABOV, William. Padrôes sociolinguísticos. São Paulo: Parábola, 2008.
} 
linguísticos é uma interpretação equivocada. $\mathrm{Na}$ verdade, foi superada a visão de língua como entidade homogênea e predominante sobre a fala:

Não podemos nos permitir qualquer passo atrás: quem quer que deseje seguir adiante no estudo da língua certamente tem que ser capaz de trabalhar neste nível de abstração [paradigma gerativista]. Ao mesmo tempo, é difícil evitar a conclusão sensata de que o objeto da linguística tem de ser, ao fim e ao cabo, o instrumento de comunicaçáo usado pela comunidade de fala [...]. (LABOV, 2008, p. 219-220) ${ }^{36}$

Labov (2008, p. 215) $)^{37}$ afirma, por um lado, que "uma área de pesquisa que tem sido incluída na 'sociolinguística' talvez seja rotulada mais adequadamente de 'sociologia da linguagem'. Lida com fatores sociais de larga escala e sua interação mútua com línguas e dialetos" e, por outro, que "este capítulo tratará do estudo da estrutura e da evolução da língua dentro do contexto social da comunidade de fala". Isso quer dizer que havia, naquele momento, a necessidade de não mais se considerar apenas a estrutura linguística, como fazia Saussure, mas também como o falante faz uso dessa estrutura no momento da comunicação e que, sendo assim, ao passo que a sociedade muda, a língua muda com ela.

As pesquisas sociolinguísticas de cunho essencialmente qualitativo são provenientes de tradições antropológicas sociais anglo-saxãs e da etnologia francesa (SILVA \& SILVEIRA, 2007) ${ }^{38}$ com preocupações culturais e psicológicas muito fortes, com vistas a "entender o outro" (DENZIN \& LINCOLN, 2006) ${ }^{39}$. Por isso, Labov $(2008)^{40}$ as considera distintas do projeto sociolinguístico a que ele se propôs.

36 LABOV, William. Padrões sociolinguísticos. São Paulo: Parábola, 2008.

37 LABOV, William. Padrões sociolinguísticos. São Paulo: Parábola, 2008.

38 SILVA, José Maria da; SILVEIRA, Emerson Sena da. Apresentação de trabalhos acadêmicos: normas e técnicas. Petrópolis, RJ: Vozes, 2007.

39 DENZIN, Norman K.; LINCOLN, Yvonna S. "A disciplina e a prática da pesquisa qualitativa”. In:__. O planejamento da pesquisa qualitativa: teorias e abordagens. Porto Alegre: Artmed, 2006. p. 15-39.

40 LABOV, William. Padróes sociolinguísticos. São Paulo: Parábola, 2008. 
Segundo Flick et. al. (apud GÜNTHER, 2006) ${ }^{41}$, a pesquisa qualitativa caracteriza-se pela "compreensão como princípio do conhecimento", pela "construção da realidade", pela "descoberta e construção de teorias" e pela "ciência baseada em textos", o que Günther (2006) ${ }^{42}$ não concebe como características sui generis da metodologia qualitativa.

Não que não haja essas preocupaçóes nas pesquisas variacionistas. Boa parte da tradição de estudos linguísticos hoje, especialmente no Brasil, deve muito de suas lucubraçóes aos estudos dialetológicos e variacionistas - que, mesmo sendo tachados de positivistas (CAMERON et al., 2006), mapearam as variedades brasileira e europeia do português, além das diversidades do próprio português brasileiro, acabando por contribuir (direta ou indiretamente) para que se entenda a cultura, a sociedade, a educação, a história de um povo. No entanto, a Sociolinguística Variacionista não é uma área assumidamente crítica e politicamente engajada como o são a Análise de Discurso (cf. FAIRCLOUGH, 2001) ${ }^{43}$ e o Feminismo (cf. HEYL, 2007) ${ }^{44}$, para citar apenas dois exemplos.

A investigação clássica de Labov (2008, p. 19-62) ${ }^{45}$ sobre a mudança sonora em uma ilha de Massachussets, Estados Unidos, apresenta-se como um exemplo de pesquisa com design quali-quanti. Labov (2008, p. 19) ${ }^{46}$ escreve: "o trabalho relatado neste capítulo diz respeito à observação direta de uma mudança sonora no contexto de vida da comunidade na qual ela ocorre”. O texto segue descrevendo a cultura, a história, a sociedade e a língua da comunidade da ilha. Ao mesmo tempo, são apresentados resultados obtidos por métodos estatísticos sobre a centralização dos ditongos /aw/ e /ay/.

41 GÜNTHER, Hartmut. Pesquisa qualitativa versus pesquisa quantitativa: esta é a questão? (Série: Planejamento de Pesquisa nas Ciências Sociais, no 07). Brasília: UnB, Laboratório de Psicologia Ambiental, 2006. Disponível em: www.psi-ambiental.net/pdf/07QualQuant. pdf, Acessado em: 17/06/ 2009.

42 GÜNTHER, Hartmut. Pesquisa qualitativa versus pesquisa quantitativa: esta é a questão? (Série: Planejamento de Pesquisa nas Ciências Sociais, no 07). Brasília: UnB, Laboratório de Psicologia Ambiental, 2006. Disponível em: www.psi-ambiental.net/pdf/07QualQuant. pdf, Acessado em: 17/06/ 2009.

43 FAIRCLOUGH, Norman. Discurso e mudança social. Brasília: Editora Universidade de Brasília, 2001.

44 HEYL, Barbara Sherman. "Ethnographic interviewing”. In: ATKINSON, P.A. et al. (Orgs.). Handbook of Ethnography. London: Sage, 2007.

45 LABOV, William. Padröes sociolinguísticos. São Paulo: Parábola, 2008.

46 LABOV, William. Padrôes sociolinguísticos. São Paulo: Parábola, 2008. 
Para entender o fenômeno, o pesquisador lançou mão de artefatos quantitativos e, para interpretar os resultados numéricos, precisou conhecer e compreender aquela comunidade e sua história por meio da imersão naquele ambiente. Segundo o próprio Labov (2008 [1972], p. 62) ${ }^{47}$, “a técnica de entrevista não foi controlada com o rigor que se esperaria: foram feitas muitas mudanças na estrutura da entrevista à medida que o estudo progredia”, postura comum em estudos qualitativos. Houve uma abordagem dialética de pesquisa para se chegar às conclusóes sobre a mudança linguística em Martha’s Vineyard.

O contrário também acontece. Pesquisadores tidos como de uma tradição de estudos qualitativos dialogam com técnicas e métodos da pesquisa quantitativa. Essa é a postura adotada por Bortoni-Ricardo (2008, p. 10, grifos da autora $)^{48}$. A autora escreve que "a pesquisa em sala de aula insere-se no campo da pesquisa social e pode ser construída de acordo com um paradigma quantitativo, que deriva do positivismo, ou com um paradigma qualitativo, que provém da tradição epistemológica conhecida como interpretativismo", e reforça com exemplo de "conciliação entre pesquisa quantitativa e pesquisa qualitativa” (BORTONI-RICARDO, 2008, p. 33) ${ }^{49}$.

Mais adiante, Bortoni-Ricardo apresenta um "modelo" de projeto de pesquisa qualitativa, cuja metodologia é "qualitativa e interpretativista" (BORTONI-RICARDO, 2008, p. 79) ${ }^{50}$, em que a autora se vale de dados censitários percentuais do SAEB para auxiliar no alcance do objetivo especificado no projeto, qual seja "identificar, descrever e analisar rotinas no trabalho pedagógico, voltadas para o desenvolvimento de habilidades linguísticas, que sejam produtivas, isto é, que resultem na aprendizagem dos alunos, manifesta em sua fala ou texto escrito" (BORTONI-RICARDO, 2008, p. 80) . $^{51}$.

47 LABOV, William. Padrões sociolinguísticos. São Paulo: Parábola, 2008.

48 BORTONI-RICARDO, Stella Maris. O professor pesquisador: introdução à pesquisa qualitativa. São Paulo: Parábola, 2008.

49 BORTONI-RICARDO, Stella Maris. O professor pesquisador: introdução à pesquisa qualitativa. São Paulo: Parábola, 2008.

50 BORTONI-RICARDO, Stella Maris. O professor pesquisador: introdução à pesquisa qualitativa. São Paulo: Parábola, 2008.

51 BORTONI-RICARDO, Stella Maris. O professor pesquisador: introdução à pesquisa qualitativa. São Paulo: Parábola, 2008. 
Realizei estudo (CARDOSO, 2005) ${ }^{52}$ sobre a variação linguística em função das dimensões social e estilística com dados obtidos de uma única falante, em seis entrevistas não estruturadas, em ambientes diversos de interação - familiares e não familiares para a colaboradora -, levando em conta pressupostos teóricos de Labov $\left(2008^{53} ; 2001^{54}\right)$ e de Bell $\left(1984^{55} ; 2001^{56}\right)$ sobre variação intrafalante.

O foco era a colaboradora da pesquisa: se ela monitorava a própria fala, se seu comportamento linguístico mudaria em função dos diversos ambientes de interação e se a pouca exposição dela ao ensino formal influenciaria na variação da concordância e na variação estilística. Para tanto, também levantei traços importantes da vida da colaboradora e me tornei uma figura constante em seu cotidiano. Ao longo do processo, ela conheceu minha orientadora de pesquisa, com quem também teve pelo menos três encontros. Neles, pôde-se observar que houve grande empatia e identificação de histórias de vida: colaboradora e orientadora eram provenientes de zona rural, casadas, com um casal de filhos e bastante extrovertidas.

As conversas com a pesquisada giravam em torno de temas como família, educação dos filhos, casamento, lazer, estudo e língua, de forma agradável e espontânea. Algo importante a ser ressaltado é que, na primeira gravação, foi dado um gravador para a colaboradora, que gravou sua voz sozinha, enquanto fazia o almoço dos patróes. O mais interessante é que ela conversava com o gravador como se ele fosse sua patroa.

O trabalho enfatiza a história de vida da colaboradora e apresenta traços muito sutis de entrevista etnográfica, como gravação de conversas não estru-

52 CARDOSO, Caroline R. Variaçâo da concordância verbal no individuo: um confronto entre o linguístico e o estilístico. Dissertação (Mestrado em Linguística) - Brasília: Universidade de Brasília, 2005.

53 LABOV, William. Padrões sociolinguísticos. São Paulo: Parábola, 2008.

54 LABOV, William. “The anatomy of style-shifting”. In: ECKERT, Penelope; RICKFORD, John R. (Orgs.). Style and Sociolinguistic variation. Cambridge: Cambridge University Press, 2001. p. 85-108.

55 BELL, Allan. "Language style as audience design". Language in society, v. 13, n. 2, p. $145-$ 204, 1984.

56 BELL, Allan. "Back in style: reworking audience design". In: ECKERT, Penelope; RICKFORD, John R. (Orgs.). Style and Sociolinguistic variation. Cambridge: Cambridge University Press, 2001. p. 139-169. 
turadas previamente, sem preocupação com o tempo da pesquisadora, mas sim com o da pesquisada e de acordo com a disponibilidade e interesse desta, mantendo certa proximidade entre as interlocutoras (HEYL, 2007) $)^{57}$.

Não há como negar que toda pesquisa, independentemente da metodologia adotada pelo pesquisador, apresenta viés pessoal e ideológico, pois "a realidade não diz como é que quer ser abordada e toda abordagem que se puder propor vai sempre parecer parcial e arbitrária” (BORGES NETO, 2004 a, p. 20 $)^{58}$. Também não há como negar nem a importância do pensamento cartesiano para a humanidade nem a importância da implantação de novos paradigmas em ciência na contemporaneidade. Não há como negar que a mudança de paradigmas afeta não só o mundo das ciências, mas também da educação, da religião, da política, da família. Portanto, a ciência, assim como todas as áreas do conhecimento humano, necessita de uma busca incessante do diálogo, do holismo, da aceitação e da compreensão da complexidade do pensamento científico, do respeito às tradiçóes e da abertura ao novo.

Segundo Günther (2006) ${ }^{59}$, “dificilmente um pesquisador adjetivado como quantitativo exclui o interesse em compreender as relaçóes complexas". Portanto, é imprescindível que o pesquisador empirista, especialmente da área da Sociolinguística, busque dosar suas hipóteses e preocupaçóes racionalistas com uma mudança de postura em relação aos sujeitos de pesquisa, em relação à ética, em relação ao desenvolvimento de pesquisas com resultados práticos para as comunidades e/ou diretamente para os seus colaboradores. E importante é ressaltar o quanto as porcentagens, as generalizaçóes, o objetivismo são importantes suportes para entender determinados contextos particulares. Nas palavras de Naro $\left(2003\right.$, p. 25) ${ }^{60}$, “o progresso da ciência linguística não está

57 HEYL, Barbara Sherman. "Ethnographic interviewing”. In: ATKINSON, P.A. et al. (Orgs.). Handbook of Ethnography. London: Sage, 2007.

58 BORGES NETO, José. Ensaios de filosofia da linguística. São Paulo: Parábola, 2004a.

59 GÜNTHER, Hartmut. Pesquisa qualitativa versus pesquisa quantitativa: esta é a questão? (Série: Planejamento de Pesquisa nas Ciências Sociais, no 07). Brasília: UnB, Laboratório de Psicologia Ambiental, 2006. Disponível em: www.psi-ambiental.net/pdf/07QualQuant. pdf, Acessado em: 17/06/ 2009.

60 NARO, Anthony Julius. "Modelos quantitativos e tratamento estatístico". In: MOLLICA, Maria Cecília; BRAGA, Maria Luiza (Orgs.). Introduçâo à Sociolinguistica: o tratamento da variação. São Paulo: Contexto, 2003. p. 15-25. 
nos números em si, mas no que a análise dos números pode trazer para nosso entendimento das línguas humanas".

Entende-se, dessa forma, como possível, desejável e perfeitamente aceitável uma relação entre a postura quantitativa e a qualitativa em pesquisas sociolinguísticas. Porque, no final das contas, segundo Nelson et al. (apud DENZIN \& LINCOLN, 2006, p. 18) ${ }^{61}$, "a escolha das práticas da pesquisa depende das perguntas que são feitas, e as perguntas dependem de seu contexto" e, ainda, "do que está disponível no contexto e do que o pesquisador pode

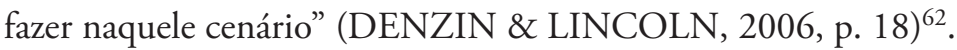

De certo modo, essas discussóes epistemológicas não são privilégio da contemporaneidade. Desde os gregos, há pelo menos duas vertentes quanto à relação entre o conhecimento humano e a "realidade" conhecida. Uma vertente que considera que há uma verdade única e objetiva, que é o objetivo da ciência; outra vertente que considera a interdependência entre conhecimento e contexto, momento histórico e circunstâncias.

No tocante à linguagem, os gregos discutiam se ela se relacionava com a realidade de forma natural ou de forma convencional - o nome podia ser uma imagem natural da coisa nomeada; o nome podia ser arbitrado ao gosto de cada um; o nome podia ser estabelecido por um legislador (BORGES NETO, 2004a, p. 71-74) ${ }^{63}$. O que se verifica, ao longo da história das ciências, é que uma ou outra vertente vigorou no fazer científico.

Chega-se, então, ao ponto crucial dessas reflexóes:

considerando os recursos materiais, temporais e pessoais disponíveis para lidar com uma determinada pergunta científica, coloca-se para o pesquisador e para sua equipe a tarefa de encontrar e usar a abordagem teórico-metodológica que permite, num mínimo de tempo, chegar a um resultado

61 DENZIN, Norman K.; LINCOLN, Yvonna S. "A disciplina e a prática da pesquisa qualitativa”. In: O planejamento da pesquisa qualitativa: teorias e abordagens. Porto Alegre: Artmed, 2006. p. 15-39.

62 DENZIN, Norman K.; LINCOLN, Yvonna S. "A disciplina e a prática da pesquisa qualitativa”. In: O planejamento da pesquisa qualitativa: teorias e abordagens. Porto Alegre: Artmed, 2006. p. 15-39.

63 BORGES NETO, José. Ensaios de filosofia da linguística. São Paulo: Parábola, 2004a. 
que melhor contribua para a compreensão do fenômeno e para o avanço do bem-estar social (GÜNTHER, 2006) ${ }^{64}$.

Do contrário, assume-se uma única postura metodológica e não se reconhece a possibilidade de caminhos alternativos para lidar com a infinidade de comportamentos, olhares e [inter]açóes existentes a respeito do objeto de estudo.

\title{
QUALITATIVE AND QUANTITATIVE RESEARCH IN SOCIOLINGUISTICS: METHODOLOGICAL DADAISM?
}

\begin{abstract}
The confluence between quantitative and qualitative research in Sociolinguistics is a methodological Dadaism? The issue here is not epistemology, because I assume that the Sociolinguistics studies the language linked to social. I want to demonstrate that the methodological approach depends on the research question, ie, the subject about which a thesis is developed.

KEY WORDS: Sociolinguistics; methodology; qualiquanti research.
\end{abstract}

Recebido em: 27/06/2012 Aprovado em: 29/01/2013

${ }^{64}$ GÜNTHER, Hartmut. Pesquisa qualitativa versus pesquisa quantitativa: esta é a questão? (Série: Planejamento de Pesquisa nas Ciências Sociais, no 07). Brasília: UnB, Laboratório de Psicologia Ambiental, 2006. Disponível em: www.psi-ambiental.net/pdf/07QualQuant. pdf, Acessado em: 17/06/ 2009. 